\title{
Representações sociais da hanseníase: um estudo psicossocial com moradores de um antigo hospital colônia
}

\author{
Social representations of Hansen's disease: a psychosocial study with residents \\ of an old hospital colony

\section{Representaciones sociales de la enfermedad de Hansen: un estudio psicosocial con los residentes de un antiguo hospital colonia}

\author{
Ádilo Lages Vieira Passos ${ }^{1}$ \\ Ludgleydson Fernandes de Araújo ${ }^{1}$
}

Recebido em 23/04/2018; revisado e aprovado em 26/07/2018; aceito em 10/08/2018.

DOI: http://dx.doi.org/10.20435/inter.v21i1.1944

\begin{abstract}
Resumo: Esta pesquisa teve como objetivo identificar e analisar as representações sociais da hanseníase entre os moradores de um hospital colônia. Diante dos resultados, verificou-se que as representações sociais da doença apresentaram ideias antagônicas, pois, ainda que ancoradas, sobretudo em conteúdos relacionados à lepra, elas também evidenciaram elementos embasados no conhecimento científico e que representam a hanseníase como qualquer outra enfermidade curável.
\end{abstract}

Palavras-chave: hanseníase; hospital colônia; representações sociais.

Abstract: This study aimed to identify and analyze the social representations of Hansen's disease among the residents of a colony hospital. Data obtained showed that the social representations of the disease presented antagonistic ideas, since, although they are anchored mainly in contents related to leprosy, they also evidenced elements based on scientific knowledge that represent Hansen's disease as any other curable disease.

Keywords: Hansen's disease; colony hospital; social representations.

Resumen: Este estudio tuvo como objetivo identificar y analizar las representaciones sociales de la enfermedad de Hansen entre los habitantes de un hospital colonia. En cuanto a los resultados, se percibió que las representaciones sociales de la enfermedad presentaron ideas antagónicas, pues, aunque ancladas sobre todo en contenidos relacionados a la lepra, también evidenciaron elementos fundamentados en el conocimiento científico y que representan la enfermedad de Hansen como cualquier otra enfermedad curable.

Palabras clave: enfermedad de Hansen; hospital colonia; representaciones sociales.

\section{INTRODUÇÃO}

A hanseníase, conhecida por séculos como lepra (CASTRO; WATANABE, 2009), é uma doença infectocontagiosa de evolução crônica que afeta, sobretudo, a pele e o sistema nervoso periférico, acarretando a redução da sensibilidade e do potencial motor dos membros superiores e inferiores (BRASIL, [s.d.]; MUNIZ et al., 2016; QUEIROZ et al., 2015).

No Brasil, desde a década de 1970, a palavra lepra deixou de figurar nos documentos oficiais para, no lugar desta, adotar-se o neologismo hanseníase (OLIVEIRA et al., 2003). Este termo, além de representar uma importante estratégia para a redução do estigma sofrido pelos hansenianos, indica também uma homenagem ao médico norueguês Gerhard Armauer Hansen, que, em 1873, descobriu o agente etiológico da infecção, o Mycobacterium leprae (M. leprae) (MONTE; PEREIRA, 2015; SIMPSON et al., 2013).

O M. leprae é um bacilo que, embora tenha um alto potencial de infectividade - capaz de infectar uma grande quantidade de pessoas -, apresenta baixa patogenicidade, haja vista que

\footnotetext{
${ }^{1}$ Universidade Federal do Piauí (UFPI), Parnaíba, Piauí, Brasil.
} 
a maioria da população possui defesas imunológicas naturais contra esta patologia (EIDT, 2004; BRASIL, [s.d.]). Assim, poucos são aqueles que realmente desenvolvem a hanseníase.

A maior suscetibilidade ao contágio pela hanseníase possui uma relação estreita com os fatores de cunho socioeconômico, na mediada em que a doença atinge, em maior proporção, as camadas populacionais que apresentam menor grau de escolaridade e que possuem dificuldade de acesso à saúde e à assistência social e sanitária (RIVERO REYES, 2013).

Com efeito, a doença de Hansen afeta principalmente as populações dos países em desenvolvimento, o que pode ser ilustrado pelo fato de que a Índia, o Brasil e a Indonésia respondem por $81 \%$ das detecções globais (WORLD HEALTH ORGANIZATION [WHO], 2015). Em 2015, os casos brasileiros ocupavam o segundo lugar no ranking mundial, quanto ao registro de pessoas com hanseníase. Aquilo correspondeu a 26.395 casos ou 13\% do total de novas notificações, ficando atrás apenas da Índia, que registrava 127.326 casos, respondendo por 60\% das deteç̧ões (WHO, 2016).

A partir destes dados e da meta da Organização Mundial da Saúde (OMS, 2016), no que se refere ao registro de menos de um caso por 10.000 habitantes, pesquisadores apontam que a hanseníase é considerada um sério problema de saúde pública no Brasil (SILVEIRA et al., 2014). Inclusive, ela é caracterizada como endêmica em vários municípios e estados nacionais.

O quadro se agrava pela persistência do alto número de pessoas diagnosticadas com algum grau de incapacidade, o que indica que a detecção da hanseníase ainda é realizada tardiamente (PALMEIRA; QUEIROZ; FERREIRA, 2013; SANTOS et al., 2016). Isso sugere a necessidade de otimização do sistema de saúde, de modo a priorizar ações de educação em saúde, exames de contatos e busca ativa tanto para diagnosticar novos casos como para resgatar os pacientes que abandonaram o tratamento.

Cabe mencionar que o diagnóstico de hanseníase ocorre, principalmente, por meio do exame dermatológico para identificar possíveis lesões ou áreas de pele com perda de sensibilidade e/ou comprometimento de nervos periféricos (SOUZA; SENA, 2014). Quando confirmado o acometimento pela doença, efetua-se o tratamento recomendado pela OMS e pelo Ministério da Saúde brasileiro, a poliquimioterapia (PQT) - uma combinação da Rifampicina, Dapsona e Clofazimina (BRASIL, [s.d.]).

Ressalta-se que a existência de um tratamento capaz de levar à cura da hanseníase é um fato recente. Durante grande parte da história da humanidade, as pessoas, até então denominadas leprosas, eram consideradas uma ameaça aos indivíduos saudáveis e, por isso, foram segregadas e isoladas do convívio social (LEITE; SAMPAIO; CALDEIRA, 2015).

Emblemáticos desse paradigma terapêutico são os antigos hospitais-colônia ou leprosários, instituições responsáveis pela materialização do isolamento dos hansenianos sob o discurso de tratamento (MONTE; PEREIRA, 2015; SIMPSON et al., 2013). Por terem sido afastadas de familiares e amigos, estas pessoas tiveram a produção da individualidade interrompida, por meio da desconstrução radical de seus referenciais, o que é a principal razão para que muitas delas ainda se encontrem em tais instituições, mesmo com o diagnóstico da cura (EIDT, 2004; SIMPSON et al., 2013; SOUZA; SENA, 2014).

Tendo em conta esta trajetória associada à lepra, mutilação, ao sofrimento e isolamento social, a hanseníase é objeto de um grande número de representações sociais (PALMEIRA; QUEIROZ; FERREIRA, 2012). Vale lembrar que a representação social é "uma forma de conhecimento, socialmente elaborada e partilhada, com um objetivo prático, e que contribui para a construção de uma realidade comum a um conjunto social" (JODELET, 2001, p. 22). 
A gênese das representações sociais (RS) envolve dois mecanismos sociocognitivos maiores: a ancoragem e a objetivação (CHAVES; SILVA, 2011). O primeiro se refere ao esforço de tornar o desconhecido em algo familiar na forma de conceitos ou ideias, ou seja, teorias do senso comum. Já a objetivação tem como atribuição dar substância às ideias, atribuindo-lhes concretude ou estrutura icônica (FRANCO, 2004).

Este processo ocorre, essencialmente, nas conversações cotidianas e tem como principais fontes: a vulgarização do conhecimento científico por meio dos meios de comunicação de massa, bem como os valores, conceitos, imagens e estereótipos que circulam no meio em que os indivíduos estão inseridos (MOSCOVICl, 2007).

Congruente à discussão, a Teoria das Representações Sociais (TRS) tem como princípio norteador investigar, compreender e intervir sobre o mundo real, especialmente no que tange às questões sociais que mais preocupam e ocupam as pessoas no dia a dia (LAHLOU, 2014). Isso quase sempre aponta para a abordagem de questões relacionadas à educação e à saúde.

Especificamente no campo da saúde, entender uma doença como representação significa tomá-la como uma construção social dinâmica, determinada por processos históricos e sociais inerentes a um grupo social, haja vista que as representações da enfermidade constituem a matéria sobre a qual as pessoas formulam suas interpretações e dão sentido a suas experiências (LINS, 2010).

Deste modo, a elaboração de RS não ocorre gratuitamente, mas para cumprir determinadas funções (CHAVES; SILVA, 2011). A primeira função - conhecimento - torna o mundo inteligível aos indivíduos e facilita a comunicação social. A segunda função - identitária - recorre à comparação social como base para a emergência da identidade e proteção das particularidades grupais. A terceira função - orientação - toma as representações sociais como um guia para a ação. Por fim, a função justificadora serve para explicar comportamentos adotados diante de outros grupos (ABRIC, 1998).

Assim, foi em decorrência do potencial da TRS para compreender o senso comum, ou seja, a realidade social do cotidiano, que este estudo buscou identificar e analisar as representações sociais da hanseníase entre os moradores de um hospital colônia.

\section{MÉTODO}

\subsection{Tipo da investigação}

Trata-se de um estudo exploratório e descritivo, com dados transversais.

\subsection{Participantes}

A pesquisa contou com a participação de 16 moradores de um hospital colônia $(H C)$ da Região Nordeste do Brasil. A unidade hospitalar foi inaugurada em julho de 1931 por uma sociedade beneficente, tendo sido encampada pelo então governo, em 3 de janeiro de 1940.

Os participantes da pesquisa foram 16 moradores do HC, com idades entre 48 e 85 anos ( $M=67,0$ anos; $D P=9,7)$ e que já se encontram curados da hanseníase. 0 tempo de diagnóstico da hanseníase apresentado pelos participantes foi entre 4 e 63 anos ( $M=36,42$; $D P=17,1)$; a idade quando da internação no HC variou entre 13 e 66 anos ( $M=37,56$ anos e $D P=16,20)$. 0 morador mais recente vive na instituição há 2 anos, e o mais antigo, há 56 anos ( $M=28,9$ anos; DP $=17,8)$. Os dados sociodemográficos podem ser verificados na Tabela 1. 
Tabela 1 - Características sociodemográficas dos participantes da pesquisa

\begin{tabular}{|c|c|c|c|c|c|}
\hline & (f) & $(\%)$ & & (f) & $(\%)$ \\
\hline Sexo & & & Religião & & \\
\hline Masculino & 14 & $87,5 \%$ & Católica & 11 & $68,8 \%$ \\
\hline \multirow[t]{3}{*}{ Feminino } & 2 & $12,5 \%$ & Evangélica & 1 & $6,3 \%$ \\
\hline & & & Espírita & 1 & $6,3 \%$ \\
\hline & & & Não tem & 3 & $18,8 \%$ \\
\hline Estado civil & & & Fonte de renda & & \\
\hline Solteiro(a) & 9 & $56,3 \%$ & Aposentadoria & 7 & $43,8 \%$ \\
\hline Casado(a) & 1 & $6,3 \%$ & Pensão & 5 & $31,3 \%$ \\
\hline Separado(a) ou divorciado(a) & 4 & $25,0 \%$ & Aposentadoria e pensão & 4 & $25,0 \%$ \\
\hline Viúvo(a) & 2 & $12,5 \%$ & & & \\
\hline Escolaridade & & & Renda & & \\
\hline Nunca frequentou escola & 3 & $18,8 \%$ & Até 1 salário mínimo & 5 & $31,3 \%$ \\
\hline $\begin{array}{l}\text { Ensino Fundamental } \\
\text { Incompleto }\end{array}$ & 11 & $68,8 \%$ & $\begin{array}{l}\text { Entre } 1 \text { e } 2 \text { salários } \\
\text { mínimos }\end{array}$ & 2 & $12,5 \%$ \\
\hline $\begin{array}{l}\text { Ensino Fundamental } \\
\text { Completo }\end{array}$ & 1 & $6,3 \%$ & $\begin{array}{l}\text { Entre } 2 \text { e } 3 \text { salários } \\
\text { mínimos }\end{array}$ & 8 & $50,0 \%$ \\
\hline Ensino Médio Completo & 1 & $6,3 \%$ & & & \\
\hline
\end{tabular}

Fonte: Elaborado pelos autores.

\subsection{Instrumentos}

Para a coleta de dados, foram utilizados dois instrumentos. O primeiro foi um questionário sociodemográfico para a caracterização dos participantes, com a finalidade de obter informações sobre idade, sexo, estado civil, religião, escolaridade, renda e fonte de renda, época do diagnóstico, ano em que foi morar no $\mathrm{HC}$ e diagnóstico de cura. O segundo foi uma entrevista semiestruturada, a fim de compreender as percepções dos participantes sobre a hanseníase, com a seguinte questão norteadora: "O que o(a) Sr(a). entende por hanseníase?".

\subsection{Procedimentos éticos e de coleta de dados}

A presente pesquisa foi submetida ao Comitê de Ética em Pesquisa (CEP) da Universidade Federal do Piauí, apresentando CAEE 69177017.3.0000.5669 e número do parecer de aprovação 2.311.177. Após aprovação pelo Comitê, o pesquisador contatou o HC, a fim de solicitar a autorização para realizar a pesquisa no interior da instituição. Em seguida, foi iniciada a coleta de dados de forma voluntária e anônima. Nesta oportunidade, foram esclarecidos os objetivos do estudo, bem como preenchidos os Termos de Consentimento Livre e Esclarecido (TCLE). Tais procedimentos se alinham ao que determinam as resoluções 466/2012 e 510/2016 do Conselho Nacional de Saúde (CNS). Estima-se que aproximadamente 15 minutos foram necessários para finalizar a participação dos entrevistados na pesquisa.

Os critérios de inclusão desta investigação contemplaram os participantes que possuem o diagnóstico ou vivenciaram o adoecimento por hanseníase. Além disso, os moradores do HC deveriam ser residentes do hospital por pelo menos um ano, sendo maiores de dezoito anos e com a apresentação de discurso coerente e orientado no tempo e no espaço.

$\mathrm{Na}$ época da pesquisa, o HC contava com 22 moradores. Destes, três se recusaram a participar da investigação e outros três não se enquadraram nos critérios de inclusão da pesquisa: 
um deles apresentava comprometimento cognitivo, o outro estava na instituição apenas há três meses e ainda havia um morador que, a despeito de viver no HC, nunca vivenciou o adoecimento por hanseníase.

Vale ressaltar que a coleta de dados foi realizada por um pesquisador previamente treinado e qualificado, que procedeu individualmente na residência de cada participante (no HC, cada morador tem o próprio quarto ou casa) e, neste momento, assinou-se o TCLE.

\subsection{Análise de dados}

Os dados sociodemográficos foram analisados a partir das estatísticas descritivas no software SPSS for Windows versão 21, objetivando caracterizar a amostra.

As entrevistas semiestruturadas foram submetidas a uma Classificação Hierárquica Descendente (CHD) com o auxílio do software Iramuteq versão 0.7. Cabe salientar que este tipo de análise permite a obtenção de classes lexicais, caracterizadas por vocábulos específicos e pelos segmentos de texto (ST) que possuem esses vocábulos em comum (CAMARGO; JUSTO, 2016).

\section{RESULTADOS E DISCUSSÃO}

O corpus geral foi constituído por 16 textos, separados em 232 ST, com aproveitamento de 181 ST (78,02\%), satisfazendo o critério mínimo apontado pela literatura, a saber, 75\% de aproveitamento do corpus (CAMARGO; JUSTO, 2016). Emergiram 8.001 ocorrências (palavras, formas ou vocábulos), sendo 1.335 palavras distintas e 665 com uma única ocorrência. Foram realizadas divisões sequenciais no corpus até se originarem 5 classes, porém, em razão do número de entrevistados, não foi possível estabelecer um perfil de pessoas em cada classe. A primeira partição deu origem a dois subcorpus, separando a Classe 5 das demais. A segunda divisão fragmentou o subcorpus maior, originando, por um lado, as classes 3 e 1 e, por outro, as classes 2 e 4. A partição do corpus em cinco classes pode ser observada na Figura 1. 
Figura 1 - Dendograma de classes com verbetes mais significativos para o corpus hanseníase

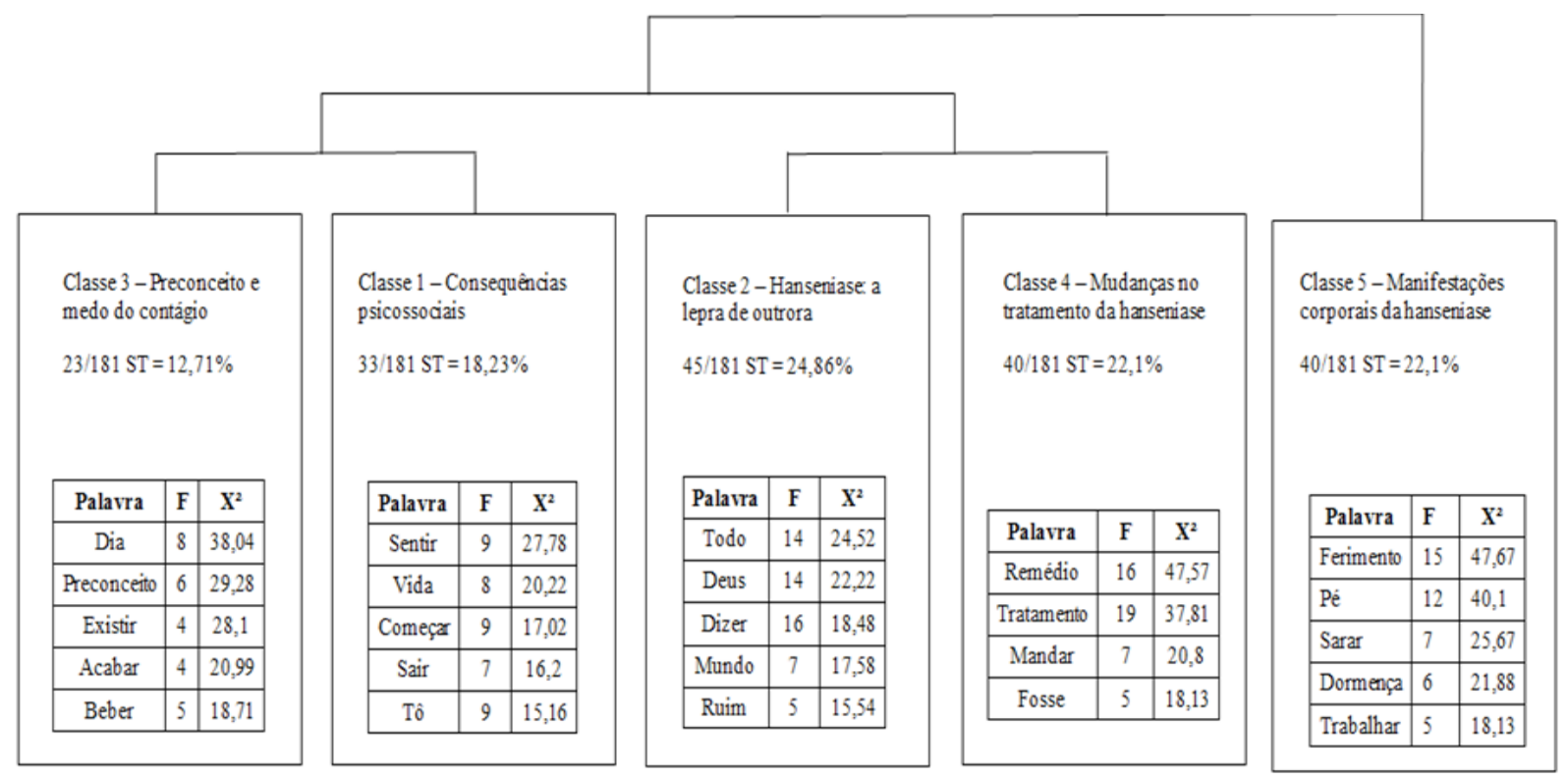

Fonte: Elaborado pelos autores

A Classe 3 é composta por 23 ST (12,71\% do total). Ela apresenta palavras e radicais no intervalo entre $X^{2}=18,71$ (Beber) e $X^{2}=38,04$ (Dia). Intitulada "Preconceito e medo do contágio", observa-se que os discursos desta classe evidenciam episódios de preconceito e discriminação, motivados, principalmente, pelo medo de ser infectado pela hanseníase. Os ST mais representativos desta classe, com base na média dos $X^{2}$ das formas ativas em cada ST, são:

"Eu, deitado numa rede, pingando suor, meio dia, meu irmão chegava na janela, pedia: rapaz, entra aí pra me dar uma aguinha pra mim beber. Aonde que ele entrou?!"; "mas o preconceito ainda hoje existe. De existir, existe, não acaba não"; "ainda existe, sim. Preconceito existe. Esse aí não se acaba assim fácil, não. Ainda existe"; "a pessoa acabar de beber a água e jogar o copo fora, então é assim como já aconteceu e isso aí é uma coisa que eu nunca esqueci e é uma coisa que dói na gente".

Uma das principais causas do preconceito enfrentado pelos hansenianos diz respeito ao medo do contágio (ZAMPARONI, 2017), pois a falta de conhecimento em torno da hanseníase contribuiu para que as pessoas infectadas com a patologia fossem consideradas uma ameaça para a sociedade dos sadios e, por isso, segregadas e isoladas do convívio social (SOUZA; SENA, 2014).

Neste contexto é que surgem os chamados hospitais-colônia ou leprosários, instituições onde o hanseniano era internado, quase sempre, contra a própria vontade e por meio de força policial (FONSECA, 2013). A estrutura desses estabelecimentos de tratamento era fechada, de modo que nestas instituições havia cassino, prefeitura, cadeia e um cemitério, tudo para que o isolamento fosse o mais eficaz possível (SOUZA; SENA, 2014).

Este medo em relação ao contágio da hanseníase tem como base os vários mitos construídos sobre a doença ao longo da história da humanidade e que, ainda nos dias atuais, contribuem para que a sociedade adote atitudes discriminatórias contra o hanseniano e sua família (BLANCO CÓRDOVA; CANGAS GARCIA, 2012; SALES et al., 2013). Assim, percebe-se que a inexistência de respostas efetivas, com vistas ao entendimento do contágio da hanseníase, faz com que as pes- 
soas continuem elaborando mecanismos cognitivos e afetivos para compreender e proteger-se dessa patologia, de modo a afastarem-se simbolicamente do seu contágio (PALMEIRA; QUEIROZ; FERREIRA, 2012).

Desta discussão, infere-se que o preconceito e o medo do contágio em relação à hanseníase têm uma ancoragem na RS da lepra (SILVEIRA; SILVA, 2006). Tal representação tem sofrido pouca alteração ao longo do tempo e leva à conjectura de que esta é uma RS hegemônica, pois se apresenta, de maneira homogênea, inquestionável e coercitiva, já que é alicerçada em valores básicos e indiscutíveis (VALA, 2006).

A Classe 1, denominada "Consequências psicossociais da hanseníase", compreende 18,23\% $(f=33 \mathrm{ST})$ do corpus total analisado. Constituída por palavras e radicais no intervalo entre $X^{2}=$ 15,16 (Tô) e $X^{2}=27,78$ (Sentir). Predomina, nesta classe, a ideia de que a hanseníase acarreta não apenas mal-estar físico, mas também impacta a esfera social e psicológica do indivíduo, o qual se materializa pelo isolamento e pela tristeza. Os ST mais representativos desta classe, com base na média dos $X^{2}$ das formas ativas em cada ST, são:

"Eu me sentia assim, senti triste, né? E saí me desanimando, né? Que não podia ficar perto das pessoas, comecei a me isolar, a me afastar das pessoas. Sentava e ficava lá longe"; "Só que eu não tô satisfeito que eu não tenho dos meus [familiares], um que me visite"; "É aquela coisa, que a gente, às vezes, tá com aquele problema, aí as pessoas se afasta da gente, né? Quando eu comecei, muita gente não queria ficar perto de mim".

Se, por um lado, a hanseníase traz importantes repercussões físicas, como ulcerações na pele e diminuição ou perda da sensibilidade nos olhos, pés e mãos, que, inclusive, podem levar a incapacidades permanentes (QUEIROZ et al., 2015), há de se destacar que o maior desafio a ser enfrentado pelas pessoas com hanseníase se encontra na esfera psicossocial, materializada pela constante ameaça do preconceito, sofrimento e abandono (ARAÚJO et al., 2016; MONTE; PEREIRA, 2015).

Em decorrência do estigma presente no adoecimento por hanseníase, o hanseniano pode sofrer discriminação nos locais de tratamento, na vizinhança e, até mesmo, na própria família (SANTOS et al., 2015). Neste sentido, os impactos sociais causados pela doença podem ocasionar a perda ou fragilização das relações comunitárias, familiares e de trabalho (MUNIZ et al., 2016).

Por outro lado, também são relevantes as consequências de cunho psicológico, tais quais: medo, ansiedade, solidão e depressão. Isso influencia na qualidade de vida, no autocuidado, na evolução da doença e de incapacidades físicas, no cuidado de si e, não raramente, no próprio sistema imunológico (SANTOS et al., 2015).

Estas consequências se agravam ainda mais quando as alterações corporais da pessoa com hanseníase tornam-se visíveis ao olhar do outro, uma vez que isto amplia a possiblidade de que esses indivíduos elaborem RS negativas acerca de si mesmos, bem como que se acentue a discriminação no meio social (PALMEIRA; QUEIROZ; FERREIRA, 2013).

Tendo em vista a função identitária das RS (ABRIC, 1998), constata-se que uma RS negativa acerca do próprio eu impacta diretamente na construção da identidade do grupo ao qual se pertence. No caso dos hansenianos, estabelece-se uma divisão entre os considerados saudáveis e os considerados doentes.

A Classe 2, "Hanseníase: a lepra de outrora", representa 24,86\% ( $f=45$ ST) do corpus total, sendo a maior classe da CHD. Compõe-se por palavras e radicais no intervalo entre $X^{2}=15,54$ (Ruim) e X $X^{2}=24,52$ (Todo). O conteúdo desta classe estabelece uma cisão entre a lepra e a han- 
seníase. Destaca-se que a primeira era marcada pelo medo do contágio e pela incurabilidade, enquanto a segunda configura-se como qualquer outra doença curável. Os ST mais representativos desta classe, com base na média dos $X^{2}$ das formas ativas em cada ST, são:

"Foi um pra São Paulo, foi não sei pra onde, aí quando vem com um jornal dizendo que não era lêlê, era hanseníase, aí mudaram a hanseníase e pronto. Aí colou hanseníase. Aí todo mundo ficou indo e foi e teve cura e tá tendo cura, graças a Deus"; "Antigamente, até as pessoas não queria nem vim aqui, tinha medo, né? Disse que pegava, era doença contagiosa, né? Agora, não é mais não. Todo mundo entra, come até com o doente, bebe"; "Morriam, morriam, né? E eu, graças a Deus, passei por isso e tô aqui, né? Quer dizer que a parte difícil ficou pra trás"; "Agora tem o remédio certo".

O acontecimento que desempenhou um papel central para a compreensão das RS da hanseníase no Brasil foi a alteração, na década de 1970, do nome lepra para o neologismo hanseníase (OLIVEIRA et al., 2003). A introdução da terminologia trouxe uma ajuda inesperada para ocultar a doença. Assim, mais que uma denominação nova para a velha enfermidade, a palavra foi entendida como significando uma patologia nova, uma forma mais branda e menos estigmatizada da afecção, até então conhecida como lepra (BARRETO et al., 2013).

Em consonância com esta discussão, uma pesquisa realizada com hansenianos reportou que, para eles, o termo hanseníase "veio para disfarçar" (SILVEIRA; SILVA, 2006). Consequentemente, sugere-se que esta palavra ameniza o impacto do diagnóstico de hanseníase, pois se distancia da carga negativa presente na expressão "lepra".

Deste modo, a mudança semântica propicia a coexistência de elementos ancorados no senso comum e que remetem à memória social da lepra, como também de conteúdos ancorados no saber científico e que se associam à hanseníase. Com efeito, a primeira denominação tem sido apontada como uma doença dos "antigos", caracterizada por feridas que não cicatrizam e que levam a mutilações das extremidades do corpo (LINS, 2010). Ainda para esta autora, a ideia de que o termo hanseníase indica uma nova doença ancora-se na lógica atual da biomedicina, fato que traz novo entendimento sobre as causas do adoecimento, as normas para o diagnóstico e a possibilidade de cura.

Esse antagonismo no campo representacional pode ser compreendido como uma tentativa de modernizar o senso comum, a partir das novas informações veiculadas pela ciência e pelas campanhas publicitárias (ainda que em menor número). Todavia tal processo certamente não se efetivará em um curto período de tempo.

A Classe 4, "Mudanças no tratamento da hanseníase", compreende 22,1\% ( $f=40$ ST). Constituída por palavras e radicais no intervalo entre $X^{2}=18,13$ (Fosse) e $X^{2}=47,57$ (Remédio). As palavras que melhor se relacionam com esta classe fazem menção à evolução sofrida pelo tratamento da hanseníase. Se, num primeiro momento, o tratamento era baseado na internação e pouca eficácia dos medicamentos, com os avanços científicos, desenvolveram-se remédios mais eficazes e o tratamento passou a ser ambulatorial. Os ST mais representativos desta classe, com base na média dos $X^{2}$ das formas ativas em cada ST, são:

"Porque tem o acompanhamento, né? Tem uma enfermeira que acompanha o tratamento daquele paciente que ele tá tomando o remédio direitinho. Tá vindo buscar as cartelas pra tomar o remédio e o resultado eu vejo aí"; "Tomava outro tipo de remédio que eu não sei dizer o nome que era minha doutora que me dava. Aí, quando eu cheguei aqui, eu entrei na sulfinha, no talidomida, lamprem, predinizona. Fiz um tratamento brusco"; "A hanseníase, hoje em dia, 
tem o remédio pra fazer o tratamento. Naquela época não tinha"; "Pessoas abandonadas pela família, que não querem, que a família não quer e faz o tratamento das pessoas, mas não fica, apanha o remédio e vai pra casa"; "Foi umas pessoas como é conhecida daqui [...] e que realmente fazia o tratamento da hanseníase com os remédio".

À semelhança do estudo de Barreto et al. (2013), grande parte dos participantes da presente pesquisa também tem da sua respectiva doença uma história de resistência, marcada por conflitos e até por certa ambivalência, ao sofrimento, ao desespero e ao tratamento, às vezes brutal, de que foram vítimas e que se prolongou por vários anos de internação. De fato, no passado, o tratamento circunscreveu a hanseníase na espacialidade da colônia, já que era muito mais uma questão social do que de saúde (SIMPSON et al., 2013).

Nesta perspectiva, é válido mencionar que, embora mudanças significativas no tratamento da hanseníase tenham se iniciado na década de 1960 (CASTRO; WATANABE, 2009), foi apenas na década de 1980 que houve uma reviravolta na política de combate à lepra, com a desativação das colônias de hansenianos e, consequentemente, com a campanha de reintegração dos doentes às suas famílias, aliada ao tratamento ambulatorial da hanseníase (PALMEIRA; QUEIROZ; FERREIRA, 2012).

Em consonância com estas transformações, as RS dos entrevistados sobre o tratamento evidenciam, de um lado, elementos negativos e que se associam ao tratamento da lepra vinculado à internação compulsória. Por outro, apresentam aspectos positivos, pois se enfatiza que, com o surgimento de medicamentos eficazes para tratar a hanseníase de forma ambulatorial, a necessidade do isolamento via internação deixou de ser uma prescrição válida.

Desta maneira, percebe-se que a valorização do novo modelo terapêutico emerge da representação da hanseníase, ancorada no saber biomédico. Tal representação concebe o tratamento como um meio capaz de restabelecer a saúde, eliminar a doença e diminuir a possibilidade de sequelas decorrentes do diagnóstico e tratamento tardios (PALMEIRA; QUEIROZ; FERREIRA, 2013).

De fato, mesmo com a persistência dos casos de hanseníase em território nacional, o tratamento via PQT, aliado às políticas de controle e eliminação, tem representado importantes avanços nas estratégias de enfrentamento da patologia, reduzindo o índice de prevalência da doença (SIMPSON et al., 2013).

A Classe 5, "Manifestações corporais da hanseníase", é constituída por 40 ST (22,1\% do total). Composta por palavras e radicais no intervalo entre $X^{2}=18,13$ (Trabalhar) e $X^{2}=47,67$ (Ferimento). Predominaram, nesta classe, concepções que associam a hanseníase a diferentes manifestações corporais, porém, ganhando destaque ferimentos que atingem os membros periféricos, que são difíceis de sarar e que podem levar a amputações. Os ST mais representativos desta classe, com base na média dos $X^{2}$ das formas ativas em cada ST, são:

"Esse ferimento sarou. Era pequeno, sarou, mas eu trabalhando de roça aqui dentro. $\mathrm{O}$ garrancho arranhava, pronto"; "Tem uns aqui que é só de caroço, mas o caroço, aquele caroço abre ferimento"; "Nos membros, aí vai bater nas mão, nos pé. Se for forma de, se for forma de caroço, ela vai dar caroço de todo jeito. Se for forma de ferimento, é ferimento de todo jeito"; "Se for forma de ferimento, ela dá ferimento, ela tira os pé, tira as mão"; "Abriu logo um ferimento, foi coisado um pedaço do meu pé e aí o ferimento nunca sarou, que as últimas falanges do meu dedo tá dentro, né?".

Os sinais e sintomas evidenciados mostram sua ancoragem ora no discurso científico ora no significante da lepra. A partir da perspectiva médica, a hanseníase é uma doença que conta com 
tratamento e cura. Já sob um enfoque cultural, esta patologia remete a símbolos negativamente carregados em praticamente todas as sociedades humanas (SOUZA; SENA, 2014).

A literatura científica aponta que a hanseníase pode envolver ulcerações nas pernas e nos pés, caroços (nódulos) no corpo, às vezes, avermelhados e dolorosos, febre, inchaço e dor nas juntas. Também pode ocorrer entupimento, sangramento, ferida e ressecamento do nariz e dos olhos (BRASIL, [s.d.]).

Por outro lado, a menção a ferimentos crônicos, bem como perdas de partes do corpo, mostra uma representação que se ancora na memória da lepra e se objetiva em imagens repulsivas e assustadoras (PALMEIRA; QUEIROZ; FERREIRA, 2013). Mas não apenas isso! Esses discursos também indicam que o diagnóstico da hanseníase foi realizado tardiamente, situação ainda corriqueira nos dias atuais e que é responsável pelas sequelas e incapacidades deixadas pela doença (SANTOS et al., 2015).

O quadro evidencia a necessidade de se intensificar o processo de socialização das informações científicas acerca da hanseníase, principalmente por meio de campanhas nos meios de comunicação de massa, bem como pelo desenvolvimento de ações de educação em saúde. Deste modo, será possível atualizar os conhecimentos sobre a doença através da construção de novas RS, o que orientará novas práticas quanto à prevenção, diagnóstico e tratamento.

\section{CONSIDERAÇÕES FINAIS}

A presente pesquisa teve por objetivo identificar e analisar as RS da hanseníase entre os moradores do HC. Os dados obtidos possibilitaram a apreensão de representações sistematizadas em cinco classes. Por um lado, observou-se que a categoria da doença deu margem para um vasto campo de representações sociais associadas, sobretudo, a elementos historicamente ligados ao acometimento pela lepra. São eles: o preconceito, o medo do contágio, a mutilação e as feridas crônicas. Isto porque, como parte da modernização do senso comum, o significante "hanseníase" não exime a lepra de toda a sua carga negativa.

Por outro lado, também se constatou a existência de elementos mais atuais, ancorados no conhecimento científico e que representam a hanseníase como qualquer outra doença passível de tratamento e cura. Em face disto, denota-se que a RS da hanseníase entre os moradores do HC apresenta-se marcada por ideias centrais antagônicas, refletindo as particularidades do grupo estudado. Com isso, ressalta-se que a maioria dos entrevistados pertence a uma geração de pacientes que passou pela internação compulsória com o diagnóstico de "lepra" e, portanto, vivenciou a transição para o novo modelo de tratamento, agora ambulatorial para o diagnóstico de "hanseníase".

Desta maneira, os moradores do HC ainda utilizam, essencialmente, suas experiências e impressões pessoais para compreender e interpretar o fenômeno da hanseníase, enquanto acontecimento capaz de gerar medo, angústia e ruptura entre o hanseniano e sua rede de relações familiares e comunitárias.

Assim, observa-se a permanência de lacunas entre o conhecimento científico e o senso comum, evidenciando a necessidade de se intensificar a difusão de informações científicas acerca da hanseníase, o que poderia ser feito por meio da realização de mais estudos sobre esta temática, bem como através de campanhas publicitárias e da educação em saúde. Estas ações poderão oportunizar a elaboração de RS mais alinhadas ao status atual da doença de 
Hansen e, assim, diminuir os impactos psicossociais causados pelo preconceito e pelo medo do contágio.

\section{REFERÊNCIAS}

ABRIC, Jean Claude. A abordagem estrutural das representações sociais. In: MOREIRA, Antonia Silva Paredes; OLIVEIRA, Denize Cristina de (Org.). Estudos interdisciplinares de representação social. Goiânia: $A B, 1998$. p. 27-38.

ARAÚJO, Daniella A. L.; BRITO, Karen K. G.; SANTANA, Emanuele M. F.; SOARES, Valéria L.; SOARES, Maria Júlia G. O. Caracterização da qualidade de vida de pessoas com hanseníase em tratamento ambulatorial. Revista de Pesquisa Cuidado é Fundamental (On-line), Rio de Janeiro, v. 8, n. 4, p. 5010-6, out./dez. 2016.

BARRETO, Jubel; GASPARONI, Jéssica M.; POLITANI, André L.; REZENDE, Lorena M. de; EDILON, Tainah S.; FERNANDES, Victor G.; LIMA,Vinícius M. Hanseníase e estigma. Hansenologia Internationalis, Bauru, SP, v. 38, n. 1-2, p. 14-25, 2013.

BLANCO CÓRDOVA, Carlos Alberto; CANGAS GARCIA, Teresa. Lepra: impacto psicossocial. Enfermería Global, Murcia, Espanha, v. 11, n. 25, p. 287-98, jan. 2012.

BRASIL. Ministério da Saúde. Sintomas. [s.d.]. Disponível em: http://portalms.saude.gov.br/saude-de-a-z/ hanseniase. Acesso em: 15 dez. 2016.

BRASIL. Ministério da Saúde. O que é hanseníase? [s.d.]. Disponível em: http://saude.gov.br/saude-de-a-z/ hanseniase. Acesso em: 14 jan. 2020.

CAMARGO, Brígido Vizeu; JUSTO, Ana Maria. Tutorial para uso do software de análise textual IRAMUTEC. Florianópolis, Laboratório de Psicologia Social da Comunicação e Cognição (LACCOS), Universidade Federal de Santa Catarina, 2016.

CASTRO, Selma Munhoz Sanches de; WATANABE, Helena Akemi Wada. Isolamento compulsório de portadores de hanseníase: memória de idosos. História, Ciências, Saúde-Manguinhos, Rio de Janeiro, v. 16, n. 2, p. 449-87, abr./jun. 2009.

CHAVES, Antonio Marcos; SILVA, Priscila Lima. Representações sociais. In: CAMINO, Leôncio et al. (Org.). Psicologia social: temas e teorias. Brasília: Technopolitik, 2011. p. 299-350.

EIDT, Letícia Maria. Breve história da hanseníase: sua expansão do mundo para as Américas, o Brasil e o Rio Grande do Sul e sua trajetória na saúde pública brasileira. Saúde e Sociedade, São Paulo, v. 13, n. 2, p. 76-88, maio/ago. 2004.

FONSECA, Cláudia. Sexualidade, gênero e afeto nos hospitais-colônias de hanseníase. Cadernos Pagu, Campinas, SP, n. 41, p. 29-40, abr. 2013.

FRANCO, Maria Laura Puglisi Barbosa. Representações sociais, ideologia e desenvolvimento da consciência. Cadernos de Pesquisa, São Paulo, v. 34, n. 121, p. 169-86, jan./abr. 2004.

JODELET, Denise. Representações sociais: um domínio em expansão. In: JODELET, Denise. (Org.). As representações sociais. Rio de Janeiro: EdUerj, 2001. p. 17-44.

LAHLOU, Saadi. Difusão das representações e inteligência coletiva distribuída. In: ALMEIDA, Angela Maria Oliveira.; SANTOS, Maria de Fátima de Souza.; TRINDADE, Zeidi Araújo (Org.). Teoria das representações sociais: 50 anos. Brasília: Scribd, 2014. p. 77-130. 
LEITE, Soraia Cristina Coelho; SAMPAIO, Cristina Andrade; CALDEIRA, Antônio Prates. "Como ferrugem em lata velha": o discurso do estigma de pacientes institucionalizados em decorrência da hanseníase. Physis: Revista de Saúde Coletiva, Rio de Janeiro, v. 25, n. 1, p. 121-38, mar. 2015.

LINS, Anete Umbelina Ferreira de Almeida. Representações sociais e hanseníase em São Domingos do Capim: um estudo de caso na Amazônia. Physis: Revista de Saúde Coletiva, Rio de Janeiro, v. 20, n. 1, p. 171-94, 2010.

MONTE, Raquel Santos; PEREIRA, Maria Lúcia Duarte. Hanseníase: representações sociais de pessoas acometidas. Revista da Rede de Enfermagem do Nordeste, Fortaleza, v. 16, n. 6, p. 863-71, nov./dez. 2015.

MOSCOVICI, Serge. Representações sociais: investigações em psicologia social. Petrópolis, RJ: Vozes, 2007.

MUNIZ, Lucas da S.; AMARAL, Irmara Géssica S.; DIAS, Thiago da S.; RODRIGUES JÚNIOR, Jorge L. The influence of assistive technology on occupational performance and satisfaction of leprosy patients with grade 2 disabilities. Revista da Sociedade Brasileira de Medicina Tropical, Uberaba, MG, v. 49, n. 5, p. 644-7, set./out. 2016.

OLIVEIRA, Maria Leide W.; MENDES, Carla Maria.; TARDIN, Rachel T.; CUNHA, Mônica D.; ARRUDA, Angela. Social representation of Hansen's disease thirty years after the term 'leprosy' was replaced in Brazil. História, Ciências, Saúde-Manguinhos, Rio de Janeiro, v. 10, (suplemento 1), p. 41-8, 2003.

ORGANIZAÇÃO MUNDIAL DA SAÚDE - OMS. Estratégia global para hanseníase 2016-2020: aceleração rumo a um mundo sem hanseníase. Genebra: World Health Organization, 2016. Disponível em: https:// apps.who.int/iris/bitstream/handle/10665/208824/9789290225201-pt.pdf. Acesso em: 2 jan. 2018.

PALMEIRA, lací Proença; QUEIROZ, Ana Beatriz Azevedo; FERREIRA, Márcia de Assunção. Marcas em si: vivenciando a dor do (auto) preconceito. Revista Brasileira de Enfermagem, Brasília, v. 66, n. 6, p. 893900, nov./dez. 2013.

PALMEIRA, lací Proença; QUEIROZ, Ana Beatriz Azevedo; FERREIRA, Márcia de Assunção. Quando o preconceito marca mais que a doença. Tempus, Actas de Saúde Coletiva, Brasília, v. 6, n. 3, p. 187-99, 2012.

QUEIROZ, Tatiane A.; CARVALHO; Francisca P. B. de; SIMPSON, Clélia A.; FERNANDES, Amélia C. L.; FIGUEIRÊDO, Débora L. de A.; KNACKFUSS, Maria Irany. Perfil clínico e epidemiológico de pacientes em reação hansênica. Revista Gaúcha de Enfermagem, Porto Alegre, v. 36, número especial, p. 185-91, 2015.

RIVERO REYES, Eduardo. Lepra: asunto de preocupación de salud mundial. Revista de Ciencias Médicas La Habana, Havana, v. 19, n. 3, p. 421-32, 2013.

SALES, Jaqueline Carvalho e Silva et al. O significado da hanseníase para o agente comunitário de saúde. Revista Interdisciplinar, Teresina, v. 6, n. 1, p. 17-24, jan./mar. 2013.

SANTOS, Allan D.; SANTOS, Márcio B.; BARRETO, Aline S.; CARVALHO, Denis da S.; ALVES, José Antonio B.; ARAÚJO, Karina C. G. M. de. Análise espacial e características epidemiológicas dos casos de hanseníase em área endêmica. Revista de Enfermagem UFPE on-line, Recife, v. 10, (suplemento 5), p. 4188-97, nov. 2016.

SANTOS, Karen da S.; FORTUNA, Cinira M.; SANTANA, Fabiana R.; GONÇALVES, Marlene F. C.; MARCIANO, Franciele M.; MATUMOTO, Silvia. Significado da hanseníase para pessoas que viveram o tratamento no período sulfônico e da poliquimioterapia. Revista Latino-Americana de Enfermagem, Ribeirão Preto, SP, v. 23, n. 4, p. 620-7, jul./ago. 2015. 
SILVEIRA, Iolanda Ruthes; SILVA, Paulo Roberto da. As representações sociais do portador de hanseníase sobre a doença. Saúde Coletiva, São Paulo, v. 12, n. 3, p. 112-7, 2006.

SILVEIRA, Mariana G. B.; COELHO, Adilson R.; RODRIGUES, Suely Maria; SOARES, Marina M.; CAMILLO, Gustavo N. Portador de hanseníase: impacto psicológico do diagnóstico. Psicologia \& Sociedade, Belo Horizonte, v. 26, n. 2, p. 517-27, 2014.

SIMPSON, Clélia A.; MIRANDA, Francisco A. N. de; MENESES, Rejane M.; CARVALHO, Icléia H. da S.; CABRAL, Ana Michele de F.; SANTOS, Vivianne R. C. dos. No habitus do antigo hospital colônia - representações sociais da hanseníase. Revista Online de Pesquisa: Cuidado é Fundamental, Rio de Janeiro, v. 5, n. 3, p. 104-13, jul./set. 2013.

SOUZA, Janice Fabiana Maia de; SENA, Teresa Christina da Cruz Bezerra de. O envelhecer institucionalizado de sujeitos sequelados pela Hanseníase da U/E Abrigo João Paulo II. Revista Kairós Gerontologia, São Paulo, v. 17, n. 1, p. 103-23, mar. 2014.

VALA, Jorge. Representações sociais e psicologia social do conhecimento quotidiano. In: VALA, Jorge; MONTEIRO, Maria Benedicta (Org.). Psicologia social. 7. ed. Lisboa: Fundação Calouste Gulbenkian, 2006. p. $187-225$.

WORLD HEALTH ORGANIZATION- WHO. Global leprosy update, 2014: time for action accountability and inclusion. Weekly Epidemiological Record, Geneva, v. 91, n. 35, p. 405-20, set. 2016. Disponível em: http:// apps.who.int/iris/bitstream/10665/249601/1/WER9135.pdf. Acesso em: 20 dez. 2017.

WORLD HEALTH ORGANIZATION- WHO. Global leprosy update, 2014: need for early case detection. Weekly Epidemiological Record, Geneva, v. 90, n. 36, p. 461-76. set. 2015. Disponível em: http://www.who.int/ wer/2015/wer9036.pdf?ua=1. Acesso em: 22 dez. 2017.

ZAMPARONI, Valdemir. Lepra: doença, isolamento e segregação no contexto colonial em Moçambique. História, Ciências, Saúde-Manguinhos, Rio de Janeiro, v. 24, n. 1, p. 13-39, jan./mar. 2017.

\section{Sobre os autores:}

Ádilo Lages Vieira Passos: Mestre em Psicologia pela Universidade Federal do Piauí (UFPI). Bacharel em Psicologia pela Faculdade Integral Diferencial (FACID DEVRY). Membro do PSIQUED, Núcleo de Pesquisa e Estudos em Desenvolvimento Humano, Psicologia Educacional e Queixa Escolar, vinculado ao CNPQ. E-mail: adilolp@hotmail.com, Orcid: http://orcid.org/0000-0003-4280-0594

Ludgleydson Fernandes de Araújo: Psicólogo, doutor em Psicologia pela Universidad de Granada (Espanha) com período sanduíche na Università di Bologna (Itália), mestre em Psicologia e Saúde pela Universidade de Granada (Espanha), mestre em Psicologia Social e especialista em Gerontologia pela UFPB. Professor orientador do Programa de Pós-Graduação (Stricto Sensu) em Psicologia da Universidade Federal do Piauí (UFPI). Bolsista de Produtividade PQ-2 em pesquisa pelo CNPq. E-mail: ludgleydson@yahoo.com.br, Orcid: http://orcid.org/0000-0003-4486-7565 
